\title{
Automation of Fixtures Using Hydraulic Power Pack for a Bogie Underframe
}

\author{
Navya K.R. ${ }^{1}$, S. Pradeep ${ }^{2}$ \\ 1. Student, M.Tech, Industrial automation and robotics, MCE, Hassan - Corresponding author \\ 2. Professor, Dept., of Mechanical Engineering, MCE, Hassan
}

\begin{abstract}
In this era of automation technologies manufacturing sectors have placed very high demands on fast and reliable production methods. This work is the evaluation \& analysis of the existing clamping system. The current system uses manual clamping of fixtures for holding the work piece in the proper position while welding process is being done on the part. The evaluated system uses hydraulic vertical swing clamps for holding the work piece driven by hydraulic power pack. Thus the new system achieves automatic and simultaneous clamping of fixtures.
\end{abstract}

Keywords: Fixtures, Manifold block, Directional control valves, Swing clamps

\section{Introduction}

The automatic clamping systems in this paper are designed to work with the hydraulic actuation system (power pack). The automation of clamps using hydraulic vertical swing clamps are designed to work in a sophisticated, precise, reliable, safe as well as accurate production methods. The clamping systems are designed such that they withstand the huge retention forces applied from the work component onto the clamping elements. The work component used is an underframe structure of a train bogie. Underframe is nothing but the base frame of a train coach. The clamping systems are designed to hold the side sills of an underframe. The welding operation is performed to weld the end frames, cross members and various other components on to the side sills of an underframe. Also the clamping systems are analysed to test the load bearing capacity of a clamping system.

Providing the proper work holding platform is an important issue in any kind of operations performed on the work component. In this way automation has played a vital role in providing a reliable and fast clamping system which will reduce the cycle time of clamping with the increase in accuracy thus decreasing the possible damages to the work piece.

\subsection{Framework of the car body structure:}

The car body of the train consists of the following principal substructures.

1. Under Frame Structure

2. End wall structure

3. Side wall Structure

4. Cab structure

5. Roof structure

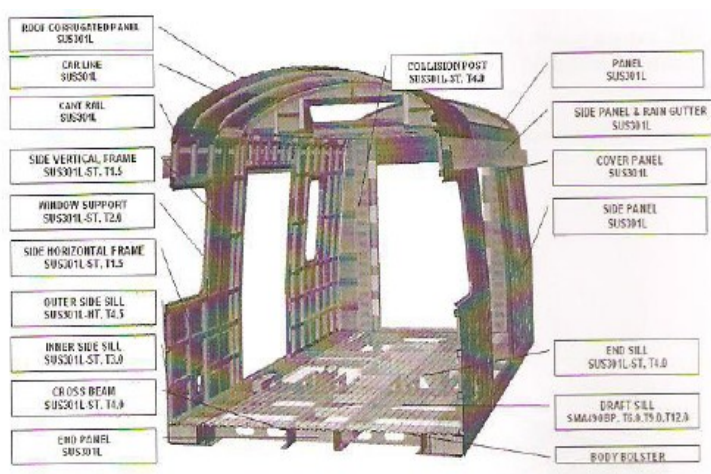

Fig 1 Bogie body structure

\section{Under Frame Structure}

The under frame structure is the primary component of the train body frame. The under frame, being foundation of car body, supports the other substructures and it is the main load bearing component.

A single under frame structure is $21700 \mathrm{~mm}$ long and $2880 \mathrm{~mm}$ wide. It consists of middle under frame and two end under frames. 


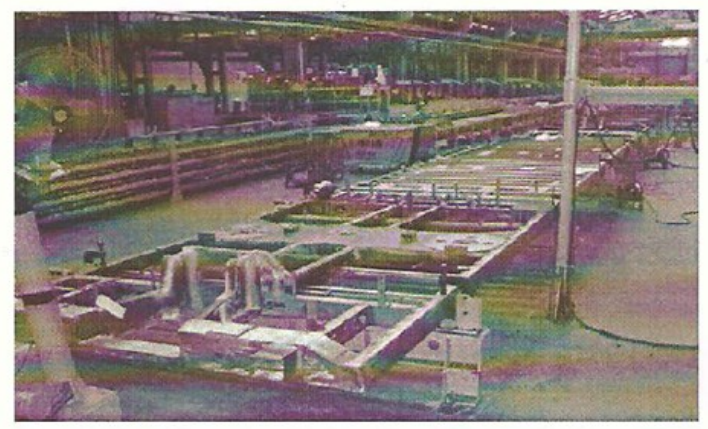

Fig .2. The assembled under frame structure

The under frame consists of central sill made of mild steel which is welded with the cross members and this assembly is welded with the side sill. Depending on the type of the car, the couplers are suitably mounted on the central sill. The bogie is mounted on the bolster (made of MS) which situated on the end under frame. The brackets are mounted underneath the end under frame to support various auxiliaries such as HVAC equipment (heating, ventilation and air conditioning), transformer, inverter, cable ducts, battery compressor, etc.,

\section{Literature Survey}

S. S. Ngu et. al., ${ }^{[1]}$ has discussed about the design of different parts of an automated high speed machine to assemble the parts of roller clamps. The roller clamp robotic assembly system performs various processes in the assembly line which include clamp body and roller feeding, inserting the roller into the clamp body, and dividing the rejected clamp and successfully assembled clamp into their own tray. They have designed a cost effective, minimum maintenance and high speed machine for the industry applications.

Tudor Paunescu et.al., ${ }^{[2]}$ has discussed about the new concepts in hydraulic work holding devices which includes the pumps that have greater energetic efficiency and are cheaper than other hydraulic power sources like electric or pneumatic power units. This kind of pump is primarily for use in flexible machining centres, in which the power source cannot remain connected to the fixture, and for power clamping on portable palletized fixtures. It is a good solution for simple applications with high pressures and relatively low fluid capacities.

U. Zuperl et. al., ${ }^{[3]}$ has designed an Intelligent Fixturing System (IFS) which is developed to hold a family of thin-walled workpieces for machining operations. This is a cost-effective system which uses off-line optimization of the clamps location and on-line adjustment of clamping forces. As adaptive clamping forces appropriate to the dynamic machining environment are employed, the IFS offer higher quality of machined parts and greater robustness to disturbances. This system incorporates a fixturing system, fixture stability model, force monitoring module, clamping force optimization algorithm and clamping control system.

Emanuele Guglielmino et. al., ${ }^{[4]}$ has discussed about switching over from electrical energy to hydraulic energy which is more powerful in robotic, high volume need applications. Switching control was not considered, and more and more accurate proportional flow/pressure control devices (servo valves etc) were developed.

Jeffrey J. Madden et. al., ${ }^{[5]}$ has discussed about the specialized fixtures needed for robotic welding to accurately hold the work piece while welding operation. They have designed and constructed a prototype welding fixture with enhanced mobility. The new fixture design reduces cycle time and operator labour while increasing functionality; and allows complex welding operations to be completed on simple two axis welding arms.

Guohua Qin et. al., ${ }^{[6]}$ has discussed about impacts of the application sequence of multi clamps on the work piece machining accuracy, they have analyzed and optimized clamping sequence. A new methodology that takes into account is the varying contact forces and friction force during clamping is presented for the first time.

M. Vural et. al., ${ }^{[7]}$ has discussed about, specially designed welding fixture for a welded steel structure. Six different types of AISI 1020 steel specimens are tested in three different welding speeds and two different cooling conditions, either at fixture or without using fixture. They have found that designed fixture has reduced amount of distortions. The preheating effect of previous weld on the next weld has increased distortions on the other side of part. Increase in distortions is directly proportional to the increase in welding speed which affects the weld heat input.

\section{Hydraulic Circuits}

A hydraulic circuit is a system comprising an interconnected set of discrete components that transport liquid. The purpose of this system is to control where fluid flows (as in a network of tubes of coolant in a thermodynamic system) or to control fluid pressure (as in hydraulic amplifiers). The approach of describing a fluid system in terms of discrete components is inspired by the success of electrical circuit theory. Just as electric circuit theory works when elements are discrete and linear, hydraulic circuit theory works best when the 
elements (passive component such as pipes or transmission lines or active components such as power packs or pumps) are discrete and linear. This usually means that hydraulic circuit analysis works best for long, thin tubes with discrete pumps, as found in chemical process flow systems or micro scale devices.

Components: The circuit comprises the following components:

Active components-Hydraulic power pack

Transmission lines- Hydraulic hoses

Passive components- Hydraulic cylinders

\section{Previous System}

This work is the evaluation of the existing system. The underframe fixture structure which was used previously includes 2 columns of fixtures and locators. It includes 9 fixtures and 9 locators in each column. Thus it includes total number of 18 fixtures and 18 locators in each underframe machining section. In the existing system the locators are operated using hydraulic automation system. The current underframe machining section set up is used to hold the undeframe structure for the welding operation. The total time taken for manual clamping is $1.4 \mathrm{hr}$.

The 3D model of the existing fixtures of the under frame structure are as shown in the figure (2).

It shows isometric and right view of the jigs holding the work component i.e. under frame structure.

Also the 3D model of the present fixtures is given in fig (3).

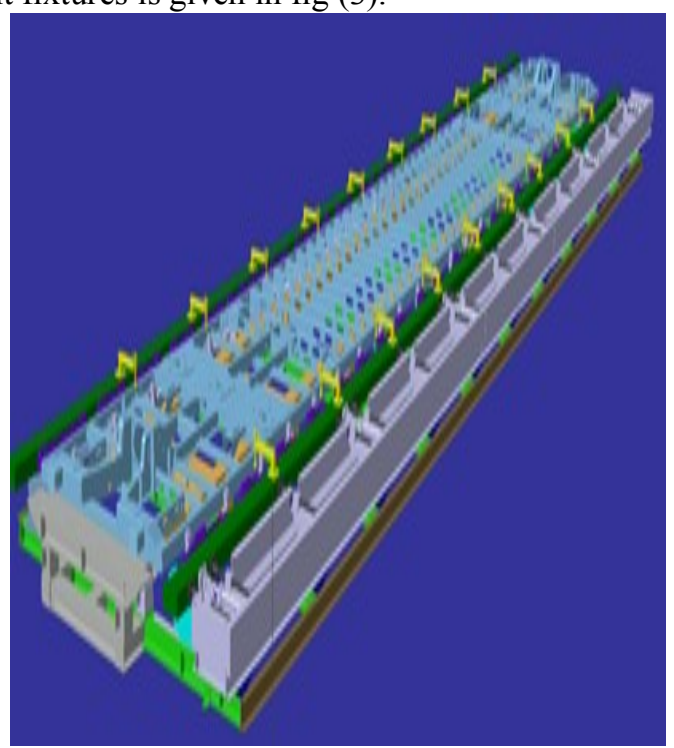

Fig 3. Isometric view of the fixtures structure

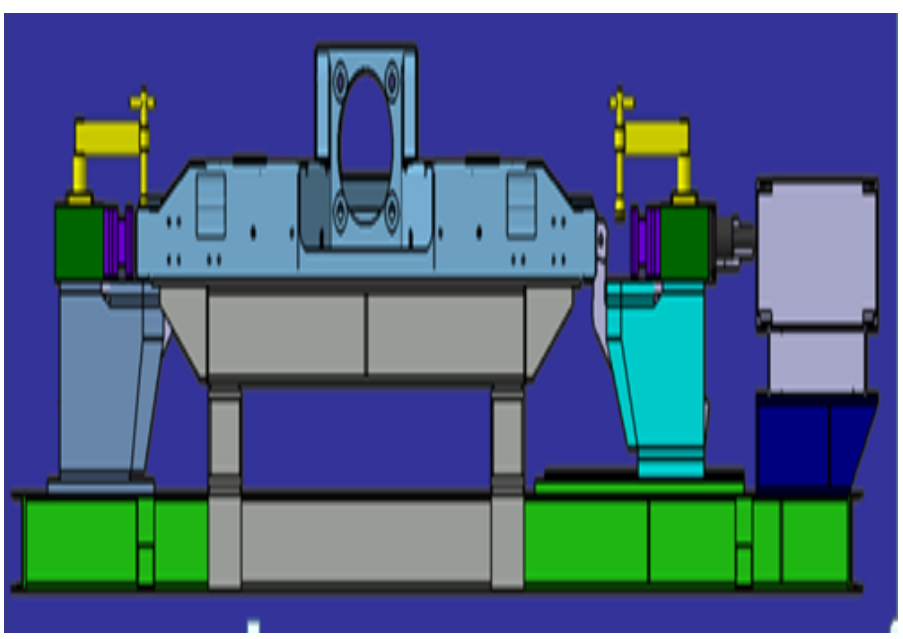

Fig 4. Right view of the fixtures structure 


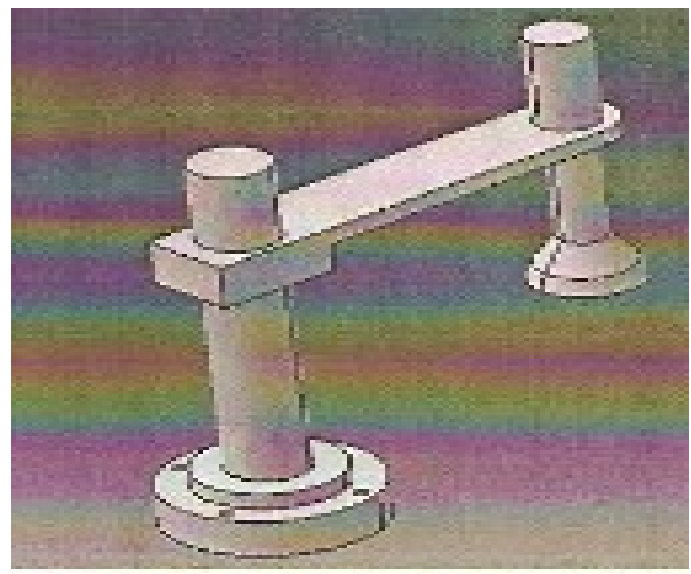

Fig. 5 Existing fixtures structure

Problem statement: The previous system utilizes human resource for clamping of jigs in the proper position on the work piece. The total time taken for clamping action to get completed is 1.4Hr. Also the jigs here are used to hold the work piece over a length of 21.7 meters. So the uniform force cannot be applied at the same time hence it might cause damage of the work piece.

\section{Proposed System}

Aim of the work: Aim of this work is to study and optimise the performance of the under frame jigs being used for the train coach production. The suggested approach would be to automate the clamping by using hydraulic system which will have reduce the cycle time of operation, eliminate human errors and may minimize the damages to the actual product at clamping locations. The total time taken to automatic clamping will be 4-6s.

This system is designed to work with automatic clamping of all the fixtures simultaneously which includes total number of 18 fixtures. tonnes.

The overall dimension of the single bogie coach is $22000(\mathrm{~L}) * 3300(\mathrm{~W}) * 3700(\mathrm{H})$ in $\mathrm{mm}$. It weighs 310

Constraints: The constraints to design the proposed system are

- To produce an economically feasible design.

- Only the existing fixtures have to be replaced excluding the work holding platform.

- All the fixtures should be clamped simultaneously.

- To produce a design such that it works within a force range of $200 \mathrm{~N}$ to $58 \mathrm{KN}$.

- To withstand the retention force produced from the work component

- To be driven using the existing hydraulic power pack this is of $16 \mathrm{MPa}$ capacity.

The methodology of work followed is

1. Hydraulic Circuit Designing

2. Modelling

3. Analysis

Force calculation of the existing jigs.

\section{Hydraulic Circuit Designing}

Since the manual clamping is done the force applied from the human being can be calculated by measuring the torque of the jigs.

The torque measured using the torque wrench is $55 \mathrm{Nm}-75 \mathrm{Nm}$.

Length of the arm $=225 \mathrm{~mm}$.

The formula used in calculating the minimum force is

Torque $=$ Length $*$ Force* Sin (angle)

Force $=$ Torque/ (length* Sin (angle))

Angle at which clamping force applied is $90^{\circ}$. 
$\therefore$ Force $=55 \mathrm{Nm} /\left(\left(225 * 10^{-3}\right) *\left(\sin \left(90^{0}\right)\right)\right.$

$\therefore$ Force $=244.6 \mathrm{~N}$

Standard bolt sizes and force applied according to Quicloc manufacturers are given in the table 1 below.

\begin{tabular}{|l|l|l|l|l|l|l|l|}
\hline Bolt Size & M1 & M5 & M10 & M15 & M20 & M25 & M30 \\
\hline $\begin{array}{l}\text { Clamping } \\
\text { Force in } \\
\mathrm{KN}\end{array}$ & 0.7 & 10 & 14.2 & 25.6 & 32.5 & 44.3 & 56.5 \\
\hline
\end{tabular}

Table 1

Considering the above mentioned table, current clamp bolt size and torque calculations we can find that

1. The standard bolt size used in the existing fixtures is M30.

2. But the minimum manual clamping force applied is $244.6 \mathrm{~N}$.

3. It shows that the retention force produced by the work piece while welding is being done on it is less than or equal to $56.5 \mathrm{KN}$.

4. Hence from the above calculations we can assume that hydraulic energy is the suitable form of energy to automate the fixtures.

\subsection{Hydraulic power pack:}

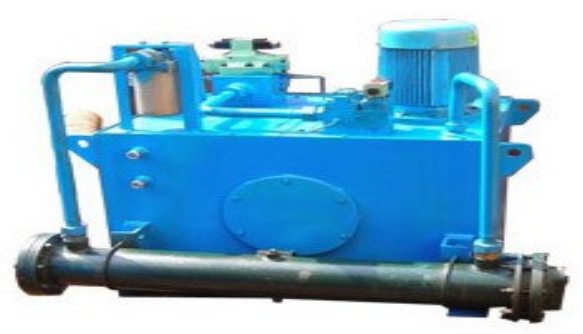

Fig 6 Hydraulic power pack

- Hydraulic power pack used is of 350 Litre's capacity made of CGJ.

- The piston pump used is A-37-F-R-01-C-K-32 which is a single pump press -16MPa, Disp-369cc, condenser type control, minimum adjustment flow of 10 cubic.cm/rev.

- It includes double acting solenoid relief valve with sub plate mounting, valve size-03, coil type-A200 max, operating pressure-25MPa, max flow-100L/min.

- It includes needle valve, electric motor, chain coupling, return filter, level gauge, Air breather, fan cooler, pressure gauge, suction strainer, magnet, thermostat, stop valve, ball valve, pressure switch, terminal box $\&$ Directional solenoid valve.

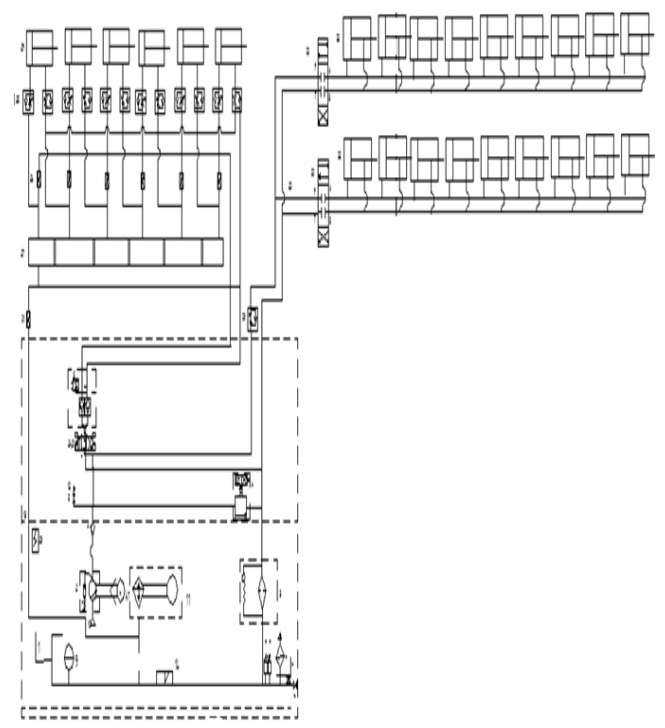

Fig. 7 Circuit diagram designed for automation 
Hydraulic tank: The hydraulic tank used is of 350 Lts capacity. The hydraulic fluid reservoir holds excess hydraulic fluid to accommodate volume changes from: cylinder extension and contraction, temperature driven expansion and contraction, and leaks. The reservoir is also designed to aid in separation of air from the fluid and also work as a heat accumulator to cover losses in the system when peak power is used. Reservoirs can also help separate dirt and other particulate from the oil, as the particulate will generally settle to the bottom of the tank. Some designs include dynamic flow channels on the fluids return path that allow for a smaller reservoir.

Piston pump: It is a pump having a reciprocating piston operating in a cylinder so as to impart motion and pressure to the fluid by direct displacement. The piston pump used is a single pump. Pressure -16MPa, Disp$369 \mathrm{cc}$, condenser type control, minimum adjustment flow of 10 cubic.cm/rev.

Check valve: It is a one-way valve, allowing an accumulator to charge and maintain its pressure after the machine is turned off.

Solenoid relief valve: A solenoid valve is an electromechanically operated valve. The valve is controlled by an electric_current through a solenoid. Here a double solenoid type, Sub plate mounting, valve size-03, Coil type A200 max, operating pressure-25Mpa, maximum flow $100 \mathrm{~L} / \mathrm{min}$.

Electric Motor: Electric power supply is a pump that is driven by an electric motor to create flow. The specifications are K5KW, 4P, 440V, 50Hz, Frame-160Lt, and RPM- 1430.

Chain coupling: A fluid coupling is a hydrodynamic device used to transmit rotating mechanical power.

Return filter: The return filter is located immediately upstream the reservoir. Its elements are sized at 40 microns to remove debris generated in the hydraulic system before the fluid is returned to the reservoir. These particles are produced by such components as cylinder rod seals and various types of valves as they ware.

Level gauge: A level gauge is used to measure the level of oil in a system to ensure fail -safe function of restricted neutral grounding system.

Air Breather: With cylinders, for instance, the volume of hydraulic fluid in the external system, as well as in the reservoir, changes. If there were no breather, varying pressure and/or partial vacuum would occur in the tank. The breather typically has some mesh in it that allows flow of air but prevents the entry of particles, such as dust.

Pressure gauge: It is nothing but a device used to measure the pressure of a liquid. It can gauge up to $250 \mathrm{Kg} / \mathrm{cm}^{2} / 3500 \mathrm{psi}$.

Suction strainer: The suction filter provides protection to the hydraulic pump from particles larger than 10 microns. You should use a suction filter if there is any likelihood of pump damage due to larger particles or pieces of dirt. For example, this may occur when it is difficult to clean the tank or if several hydraulic systems use the same tank for oil supply.

Magnet: Magnets are used to detect the position of hydraulic cylinders. Here magnet made by SMC is used.

Thermostat: One mechanical version uses a fluid that expands and contracts based on heat levels. Since this system centers on movements made by a fluid, it is known as a hydraulic thermostat.

Stop valve: Hydraulic stop valves are usually installed at the engine firewall. In the event of an engine fire, the shutoff valve is closed to prevent possible ignition of the hydraulic fluid.

Ball valve: A ball valve is a valve with a spherical disc, the part of the valve which controls the flow through it. The sphere has a hole, or port, through the middle so that when the port is in line with both ends of the valve, flow will occur. When the valve is closed, the hole is perpendicular to the ends of the valve, and flow is blocked.

Pressure switch: A pressure switch is a form of switch that closes an electrical contact when a certain set pressure has been reached on its input. The switch may be designed to make contact either on pressure rise or on pressure fall.

Directional solenoid valve: Directional control valves are one of the most fundamental parts in hydraulic machinery as well and pneumatic machinery. They allow fluid flow into different paths from one or more 
sources. It consists of a spool inside a cylinder which is electrically controlled. The movement of the spool restricts or permits the flow, thus it controls the fluid flow.

Pilot check valve: The Pilot-Operated Check Valve block represents a hydraulic pilot-operated check valve as a data-sheet-based model. The purpose of the check valve is to permit flow in one direction and block it in the opposite direction.

Throttle and check valve: A control valve that regulates the variable amount of fluid that is supplied to another fluid component such as an actuator.

Hydraulic cylinder: Cylinders are linear actuation devices that are typically used to keep a work piece stationary or move work piece into position. They provide axial clamping force proportional to the hydraulic pressure applied.

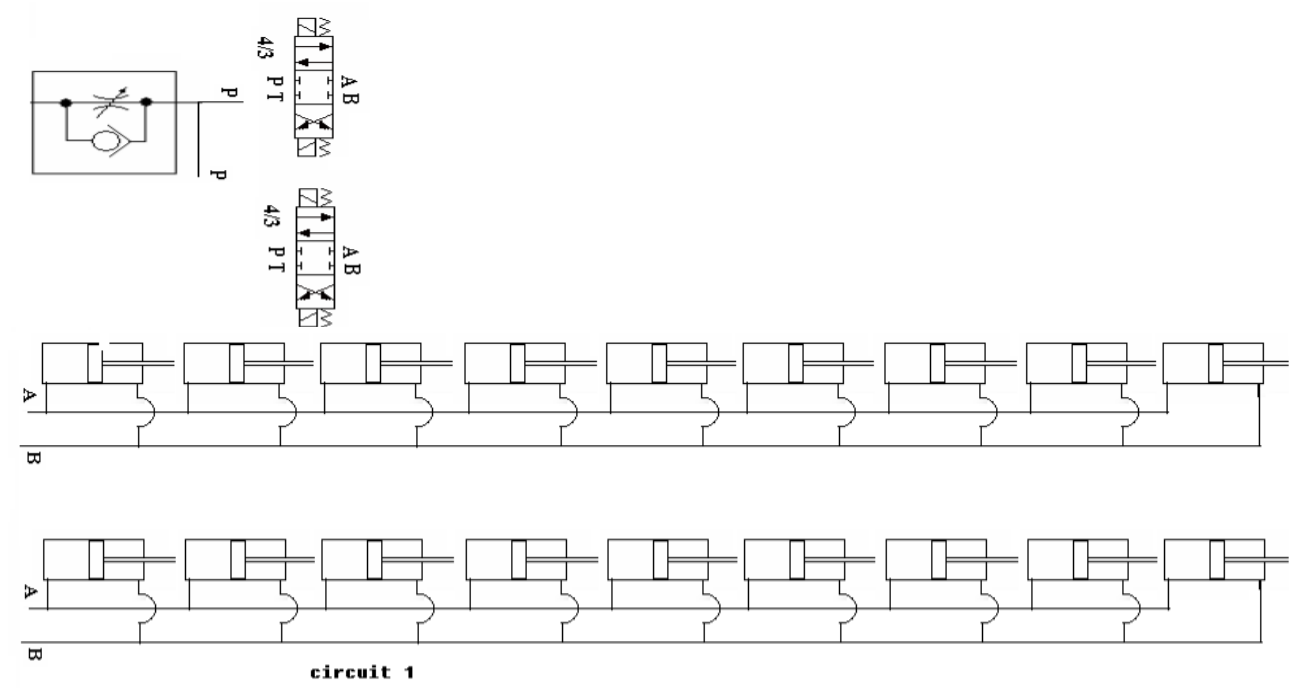

Fig. 8 Circuit designed for automation

\section{Designing of Hydraulic cylinder jigs for automatic clamping: \\ Double acting solenoid valve $[4 / 3$ valve]:}

Three-Position Four-Way valve has three different valve operator positions, left, center, and right position. It is described as a four-way valve because there are four separate fluid flow paths or ports. They are commonly referred to as "P", "T", "A", \& "B". "P" refers to the pressure port, "T" is the tank, and "A" \& "B" are the two working branches of the circuit, which are typically connected to a clamp. When the valve operator is in the left or right position, the valve directs the fluid flow thru two separate flow paths at the same time. One position sends fluid from the pump ("P") path to the working ("A") side of an actuator while the path from the opposite ("B") side of the actuator is directed back to ("T") tank. When the valve is shifted to the opposite position, the internal flow paths are reversed, sending fluid from "P" to "B" and "A" to " $T$ ".

The third or center position of a three-way valve allows for various circuit control operations or functions. Here $4 / 3$ closed centre valve is used which blocks all internal fluid paths ("P", "T", "A", \&"B") so that no flow is permitted from either the pump or the actuator when in the center position. The solenoid version of this configuration has a mechanical spring to return the operator to the center position when there is no electrical signal. A $4 / 3$ directional control valve will have four ports and three spool positions.

The circuit developed is a closed loop circuit which makes the clamp to be in clamped position only even in the case of power loss.

\section{Solenoid operated}

These valves make use of electromechanical solenoid for sliding of the spool. Because simple application of electrical power provides control, these valves are used.

Here in the existing production set up 2 rows of jigs are used i.e. at both the sides. Each row consists of 9 jigs. Therefore $2 \mathrm{DCV}$ are used which are connected to the input from existing power pack. 


\subsection{Hydraulic swing clamp:}

- Hydraulic clamp used is a vertical swing clamp which gives high clamping force and used in heavy duty fixtures.

- It is a compact design with higher clamping force.

- $\quad$ Ensures easy component loading and unloading.

- $\quad$ Since the component will be loaded from the above for the ease of loading the cylinders gives an ample clearance of $75^{\circ}$.

Hydraulic clamp used is of $56.4 \mathrm{KN}$ force @ $150 \mathrm{Bar}$, piston diameter is of $80 / 45 \mathrm{~mm}$, Stroke+ +0.5 is 65 \& Reserve stroke is $3 \mathrm{~mm}$. Oil volume in CC is 326.5

\section{Modelling}

The following figures show the clamped \& de-clamped position of the vertical swing clamp.

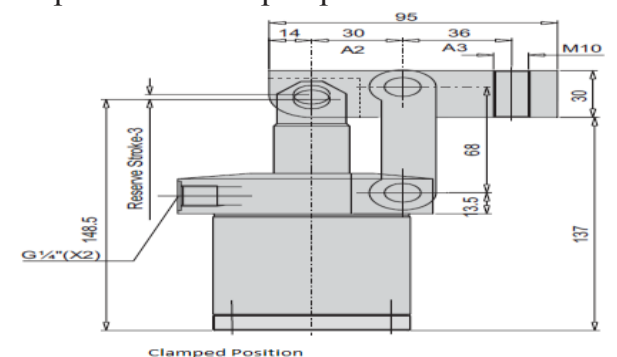

Fig.9 Clamped Position

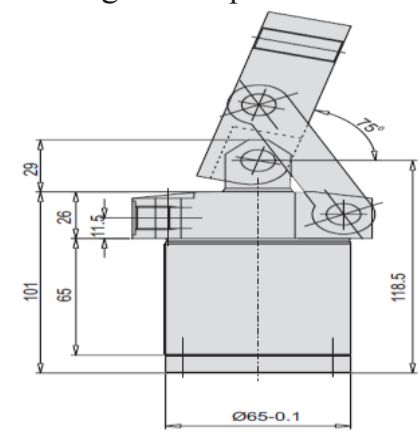

Fig. 10 De-clamped position

The vertical swing clamp used is as shown in the figure below:

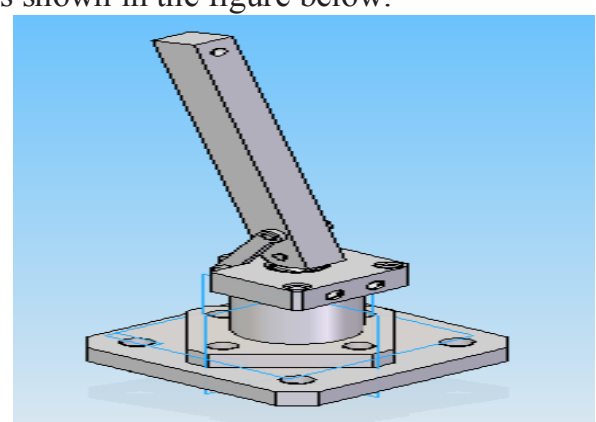

Fig. 11 Isometric view of the subassembly structure

Assembly of the vertical swing clamp onto the existing work holding platform:

Step 1: Place a spacer plate of $100 \mathrm{~mm}$ w, $100 \mathrm{~mm} \mathrm{1,} \mathrm{onto} \mathrm{the} \mathrm{existing} \mathrm{spacer} \mathrm{plate} \mathrm{with} \mathrm{M16} \mathrm{bolts.}$

Step2: Place the hydraulic cylinder onto the spacer plate located in the previous plate as shown in the above figure.

The final assembled model of the renewed work station will be as shown in the 3D model below: 


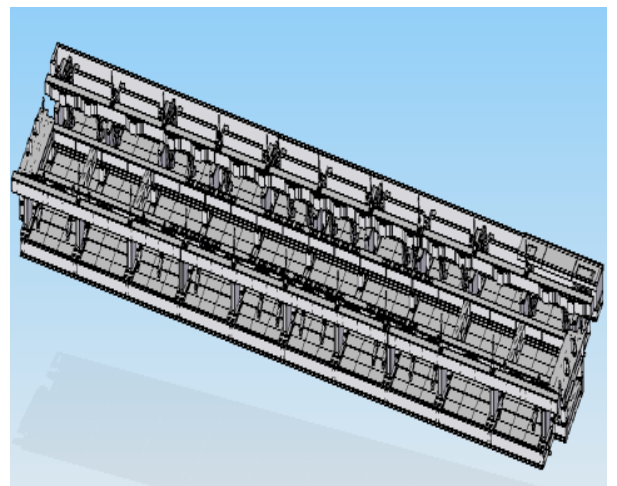

Fig. 12 Isometric view of the final assembly

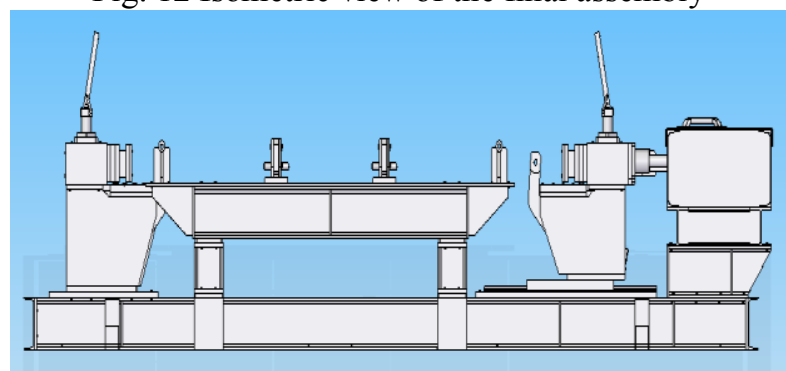

Fig.13 Right view of the final assembly

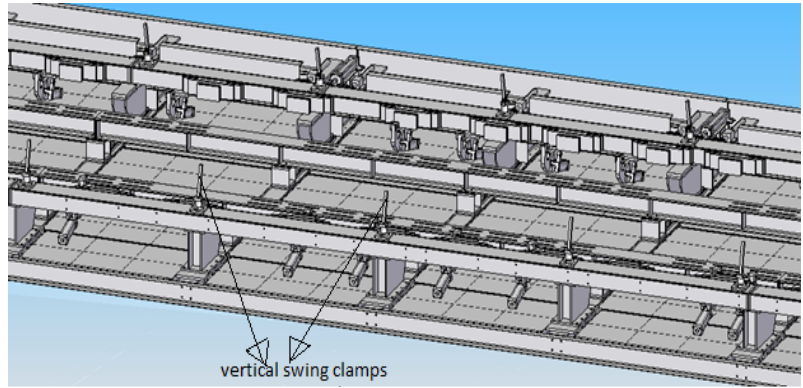

Fig. 14 Sectioned view of the final assembly

Selection of the manifold blocks to house the cylinders and fluid flow pipe size calculations.

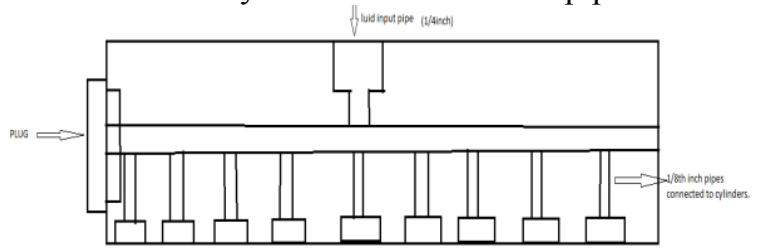

Fig. 15 Manifold block

The housing of DCV's and Cylinders will be done with 2 manifold blocks in which each can house 9 cylinders. The piping from the reservoir will be $1 / 4^{\text {th }}$ and that of each cylinder will be of $1 / 8^{\text {th }}$ inch.

\section{Analysis}

The model is complex in nature, thereby making conventional analysis close to impossible. Thus I have opted for finite element analysis of the model.

Specifications of the Material used for the under frame structure:

Material: MS grade A

Young's modulus (E): $30 \mathrm{e} 6$

Poisson ratio: 0.27 


\subsection{Meshing and analysis of the swing clamp using Hypermesh and Ansys software}

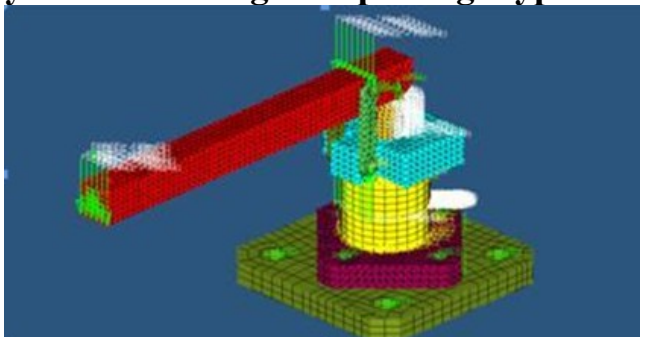

Fig. 7.1 Complete meshed hydraulic vertical swing clamp.

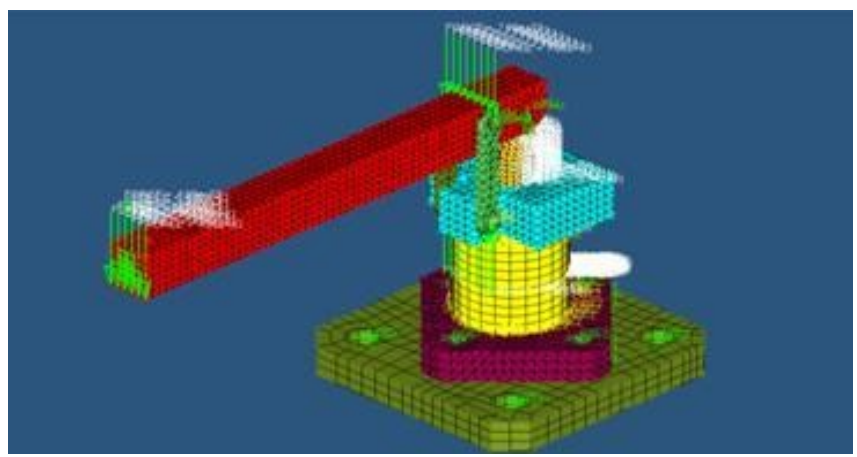

The figure 7.1 shows the completely meshed FE model of the hydraulic vertical swing clamp.

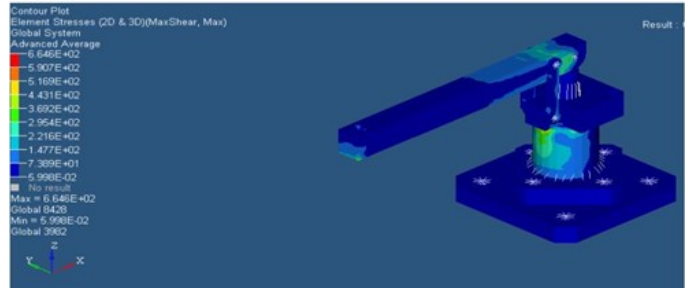

Fig. 7.7 Von-mises result of maximum elemental shear stress.

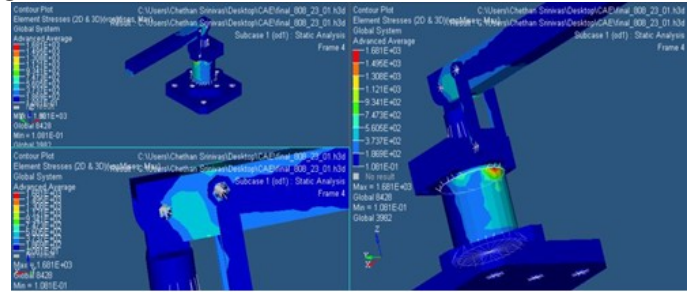

Fig.7.3 Von-mises curve of elemental shear stress at joints.

\subsection{Results}

Displacement (magnitude) of the clamp

Maximum- 8.938E-01

Minimum- 2.688E-16

Shear stress of the clamp

Maximum-6.646E+02

Minimum-5.998E-02

From the above results it is concluded that, the swing clamp designed can tolerate the maximum shear stress of $6.646 \mathrm{E}+02$ and Maximum displacement of 8.938E-01. From the 3 dimensional analysis results, it can be concluded that the swing clamp can withstand the possible retention forces applied from the work component.

\subsection{Advantages of the system}

\section{Advantages And Disadvantages}

The advantages of the proposed system are as follows:

Reduces cycle time.

Reduces labour requirement.

Simplicity of the system.

Increases flexibility. 
Ensures accuracy.

\subsection{Disadvantages of the system}

The disadvantages of the proposed system are as follows:

It requires regular maintenances.

Load/unload time may increased slightly because of the need to connect the hydraulic hoses.

\section{Conclusions}

Implementation of this project eliminates the need of human operator for clamping of jigs. It reduces the cycle time. It gives an economically feasible design. Also ensures accurate \& efficient clamping of jigs. The suggested system helps in achieving sophisticated, precise, reliable, safe as well as accurate production methods. The clamping systems are designed such that they withstand the huge retention forces applied from the work component onto the clamping elements.

\section{References}

[1] S. S. Ngu, L. C. Kho, T. P. Tan \& M. S. Osman, "Design of the Roller Clamp Robotic Assembly", World Academy of Science, Engineering and Technology, Vol-68, 2012.

[2] Tudor Paunescu, "New solutions for driving the hydraulic fixtures", International Journal of Systems Applications, Engineering \& Development, Issue 5, Volume 5, 2011.

[3] U. Zuperl, F. Cus \& D. Vukelic, "Variable clamping force control for an intelligent fixturing", Journal of Production Engineering, Vol-14, February 2011.

[4] Emanuele Guglielmino, Claudio Semini, Helmut Kogler, Rudolf Scheidl \& Darwin G. Caldwell, "Power Hydraulics - Switched Mode Control of Hydraulic Actuation", IEEE/RSJ International Conference on Intelligent Robots and Systems on October 18-22, 2010, Taipei, Taiwan.

[5] Jeffrey J. Madden, P. Martin, Stowell Peilin, Wu Hongmiao \& Li Lu He, "Welding Fixture with Active Position Adapting Functions", Huohzong Institute of Technology, 7/31/2007.

[6] Guohua Qin, "Analysis and Optimal Design of Fixture Clamping Sequence", Sino-French Laboratory of Concurrent Engineering, Department of Aircraft Manufacturing Engineering, Northwestern Polytechnic University, 482 / Vol. 128, MAY 2006.

[7] M. Vural, H.F. Muzafferoglu \& U.C. Tapici, "The effect of welding fixtures on welding distortions", Mechanical Engineering Department, Istanbul Technical University, Inonu Caddesi, No: 87/34437 Istanbul Turkey International OCSCO, World Press 15.11.2006. 